\title{
Toxicological evaluation of preservative-containing and preservative-free topical prostaglandin analogues on a three-dimensional-reconstituted corneal epithelium system
}

\author{
Hong Liang, 1,2,3,4,5 Aude Pauly, 2,3,4,5 Luisa Riancho, 2,3,4,5 Christophe Baudouin, 1,2,3,4,5,6 \\ Françoise Brignole-Baudouin 2,3,4,5,7
}

'Department of Ophthalmology III, Quinze-Vingts National Ophthalmology Hospital, Paris, France

${ }^{2}$ Institut National de la Santé et de la Recherche Médicale, U968, Paris, France

${ }^{3}$ Université Pierre et Marie Curie University Paris, France

${ }^{4}$ Unité Mixte de Recherche en Santé 968, Institut de la Vision, Paris, France

${ }^{5}$ Centre National de la Recherche Scientifique, Unité Mixte de Recherche 7210, Paris, France

${ }^{6}$ Ambroise Paré Hospital, APHP, University of Versailles Saint-Quentin-en-Yvelines, Versailles, France ${ }^{7}$ Department of Toxicology, Faculty of Biological and Pharmacological Sciences, Paris, France

\section{Correspondence to} Dr Françoise Brignole-Baudouin, UMR S968, INSERM, Institut de la Vision, 17 Rue Moreau, Paris 75012. France: frbaudouin@aol.com

Accepted 2 January 2011 Published Online First 22 March 2011

\section{ABSTRACT}

Aims Using an established three-dimensional (3D) toxicological model based on reconstituted human corneal epithelium (HCE), this study investigated the tolerability of four topical intraocular-pressure-lowering agents: the commercial solutions of benzalkonium chloride (BAC)-containing $0.005 \%$ latanoprost, $0.004 \%$ travoprost, $0.03 \%$ bimatoprost containing $0.02 \%, 0.015 \%$ and $0.005 \% \mathrm{BAC}$, respectively, and the preservative-free (PF) tafluprost. Solutions of $0.01 \%$ and $0.02 \%$ BAC alone were also evaluated for comparison.

Methods The 3D-HCEs were treated with solutions for $24 \mathrm{~h}$ followed or not by a $24 \mathrm{~h}$ recovery period. We used a modified MTT (3(4,5-dimethylthiazol-2-y))-2,5diphenyltetrazolium bromide) procedure to assess cell viability in the HCE. Frozen sections of HCE were analysed using fluorescence microscopy for the evaluation of apoptosis (terminal deoxynucleotidyl transferase mediated dUTP nick end labelling), inflammation (ICAM-1) and proliferation (Ki67). Corneal epithelial tight junctions loccludin and tight junction protein 1 (zona occludens 1)) were also assessed by en face confocal microscopy in response to the different eye-drops.

Results The MTT test revealed that the cytotoxicity of antiglaucoma eye-drops was primarily related to the concentration of their common BAC preservative $10.02 \%$ BAC-latanoprost $>0.015 \%$ BAC-travoprost $>0.005 \%$ BAC-bimatoprost). PF-tafluprost did not induce any obvious cytotoxicity, showed the least expression of inflammatory or apoptotic markers and revealed preservation of membrane immunostaining of tight junction proteins in comparison with BAC-containing solutions.

Conclusion The toxicological model of the 3D reconstructed corneal epithelia model confirmed the ocular surface cytotoxicity of BAC-containing antiglaucomatous solutions. Compared with the formulations containing the toxic preservative BAC, PF-tafluprost was well tolerated without inducing significant corneal epithelium deterioration.

\section{INTRODUCTION}

Tafluprost is a newly synthesised prostaglandin F2 $\alpha$-agonist without any toxic preservative. ${ }^{1}$ It demonstrated no cytotoxicity in human conjunctival epithelial cell lines ${ }^{2}$ and was well tolerated following short- and repeated instillations in rabbits. ${ }^{3}$ The problems raised by potentially toxic glaucoma treatments should receive more attention owing to the increased number of patients in the world, lifespan of treatments that require not only efficacy, but also safety, good tolerability and optimal compliance for patients.

Supplied by SkinEthic Laboratories (Nice, France), the reconstructed three-dimensional (3D) model of human corneal epithelium (HCE) is an appropriate alternative toxicological method to the classical Draize test in rabbits. ${ }^{4}$ It was proven to have the same characteristics as the corneal epithelium of the human eye in morphology and thickness, and is suitable for investigating the undesired effects of ophthalmic drugs. ${ }^{5}$ The objective of this study was to investigate in this 3D-HCE system the tissue changes after the treatment of the currently available commercial prostaglandin (PG)-derived eye-drops, namely the commercial solutions of $0.005 \%$ latanoprost, $0.004 \%$ travoprost, $0.03 \%$ bimatoprost (containing $0.020 \%, 0.015 \%$ and $0.005 \%$ of benzalkonium chloride (BAC), respectively) and preservative-free (PF) tafluprost. We analysed a panel of five selected biomarkers in order to assess the phenomena of apoptosis, inflammation, proliferation and tight junction impairment after a contact with the different antiglaucoma eye-drops, which would contribute to a better understanding of human corneal cell reactions following topical antiglaucoma treatments.

\section{MATERIALS AND METHODS}

Tissue model and antiglaucoma solution treatments The 3D-HCE model was supplied by SkinEthic Laboratories and consists of immortalised HCE cells grown vertically on a $0.5 \mathrm{~cm}^{2}$ insert permeable polycarbonate filter. All the experiments were conducted as previously published ${ }^{5}: 30 \mu$ l of sterile phosphate-buffered saline (PBS) used as a negative control solution, BAC solutions at $0.020 \%$ and $0.010 \%$ used as positive controls and the commercial solutions of $0.020 \%$ BAC-containing latanoprost (Xalatan; Pfizer, New York), 0.015\% BAC-containing travoprost (Travatan, Alcon, Texas), $\quad 0.005 \%$ BAC-containing bimatoprost (Lumigan, Allergan, California) or PF-tafluprost (Taflotan, Santen Oy, Tampere, Finland) were applied on the apical surface of 3D-HCE for $24 \mathrm{~h}$ and $24 \mathrm{~h}$ followed by an additional $24 \mathrm{~h}$ recovery period $(24 h+24 h$ recovery). The recovery period (24 h) was chosen in order to observe if toxic effects on HCE were reversible or not. 
Six series of 3D-HCE were used for each solution: two series for cell viability MTT (3(4,5-dimethylthiazol-2-yl)-2,5-diphenyltetrazolium bromide) testing, two series for immunohistological analyses on cryosections, and two series for immunofluorescent labelling on the most superficial layers of 3D-HCE by en face confocal microscopic analyses.

\section{Modified MTT test}

The experiments were conducted in triplicate. The 3D-HCEs were transferred to 24 -well plates containing $300 \mu \mathrm{l}$ of the MTT solution at $0.5 \mathrm{~g} / \mathrm{ml}$ in culture medium with the application onto the apical surface. After the $3 \mathrm{~h}$ incubation at $37^{\circ} \mathrm{C}$, the 3D-HCEs were incubated with $750 \mu \mathrm{l}$ of isopropanol. After agitation for $2 \mathrm{~h}$, the results were analysed by the optical density (OD, absorbance) at $570 \mathrm{~nm}$ versus OD690 $\mathrm{nm}$ and expressed as a percentage of cell viability compared with the negative control, PBS. Analyses were performed using Safire technology (Tecan, Lyon, France).

\section{Immunofluorescence analyses}

After incubations with different solutions, the 3D-HCE samples were transferred into Petri dishes containing PBS to be separated into two pieces using a surgical scalpel. One piece of tissue was embedded in optimal cutting temperature embedding medium (Tissue-Tek, Miles, Elkhart, Indiana) and frozen at $-80^{\circ} \mathrm{C}$ for future $10 \mu \mathrm{m}$ vertical cryosections. The other piece was fixed in $4 \%$ paraformaldehyde (PFA) for 20 min before immunofluorescent labelling of the tight junction proteins occludin and tight junction protein 1 (zonula occludens 1, ZO-1).

Detection of apoptosis (terminal deoxynucleotidyl transferase mediated dUTP nick end labelling (TUNEL) assay), inflammation (CD54) and proliferation (Ki67) on 3D-HCE cryosections

Apoptosis and TUNEL assay

A TUNEL kit containing TUNEL enzyme and TUNEL label (Roche Diagnostics, Meylan, France) was used to detect apoptosis in the tissue layers. The nuclei were labelled with 4',6-Diamidino-2-phenylindole dihydrochloride, and the cryosections were mounted in an antifade medium (Vectashield; Vector Laboratories, Burlingame, California).

\section{CD54 (ICAM-1) and Ki67 immunostainings}

The samples were first fixed with 4\% PFA for $10 \mathrm{~min}$ and then permeabilised with 0.01\%-diluted Triton X100 (Sigma Chemical Company, Saint Louis, Missouri) for $5 \mathrm{~min}$. The following primary antibodies were incubated: mouse antihuman ICAM-1 (IgG1, BD Biosciences, Pharmingen, San Diego, California; 1:100), mouse antihuman Ki67 (Immunotech, Marseilles, France; 1:25) and negative isotypic control mouse IgG1 (BD Biosciences). Alexa 488 conjugated-goat antimouse IgG at a 1:500 dilution (Invitrogen-Molecular Probes, Eugene, Oregon) was used as a second antibody. The nuclei were labelled with propidium iodide (PI) and cryosections were mounted. Samples were analysed under a laser confocal microscope equipped with a digital camera (E800, PCM 2000; Nikon, Champigny-surMarne, France). The immunopositive cells were counted under a $\times 20$ objective of the microscope in three different areas, and the results were calculated as the average of counts, and finally presented as cells/field ( $\times 20$ objective) after each treatment.

\section{Confocal immunofluorescence on entire epithelia for tight junction} staining

The rabbit antihuman occludin (IgG1, Dako, Glostrup, Denmark; 1:100 dilution) and rabbit antihuman ZO-1 (IgG1,
Santa Cruz Biotechnology, Santa Cruz, California) were used for tight junction staining. Alexa 488-conjugated goat antimouse was used as a second antibody, and finally nuclei were labelled with 4',6-diamidino-2-phenylindole. Samples were then analysed under a laser confocal microscope (E800, PCM 2000, Nikon) for detecting occludin and ZO-1 expressions.

\section{Quantification and statistical analysis}

TUNEL-, ICAM-1- and Ki67-positive cells were quantified manually, using a microscopic grid on images under $\times 400$ magnification. The results were expressed as mean cell number per field (cells/field). SDs were indicated.

Control and treatment groups for MTT data and immunopositive cell counts were compared using a two-way analysis of variance (ANOVA) followed by the Fisher adjustment (Statview V; SAS Institute, Cary, North Carolina).

\section{RESULTS}

\section{Cell viability: MTT test}

PBS that was used as negative control did not affect the cell viability either at $24 \mathrm{~h}$ or at $24 \mathrm{~h}+24 \mathrm{~h}$ recovery (figure 1). PF-tafluprost showed the same level of cell viability as PBS at $24 \mathrm{~h}(90.2 \%)$ and at $24 \mathrm{~h}+24 \mathrm{~h}$ recovery $(100 \%)$ without any statistically significant differences compared with $\mathrm{PBS}$. The preservative solutions of BAC at $0.010 \%$ and $0.020 \%$ induced a cell viability decrease at $24 \mathrm{~h}(65.9 \%$ and $42.5 \%$ respectively, $\mathrm{p}<0.01$ compared with $\mathrm{PBS})$ and at $24 \mathrm{~h}+24 \mathrm{~h}$ recovery $(62.9 \%$ and $43.4 \%$ respectively, $p<0.01$ compared with PBS).

The preservative-containing antiglaucoma solutions induced a BAC-concentration-dependent decrease in cell viability: at $24 \mathrm{~h}, 85.5 \%$ for $0.005 \%$ BAC-bimatoprost, $75.5 \%$ for $0.015 \%$ BAC-travoprost $(p<0.01$ compared with $\mathrm{PBS}$ group) and

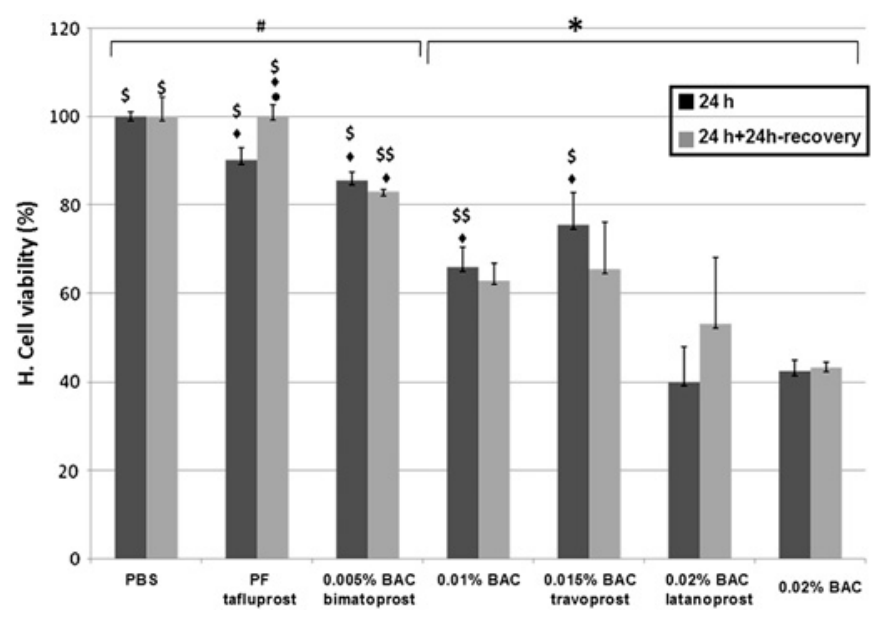

Figure 1 Cell-viability MTT 3(4,5-dimethylthiazol-2-yl)-2,5-diphenyltetrazolium bromide) test: cell viability of phosphate-buffered saline (PBS)-, preservative-free (PF)-tafluprost-, $0.005 \%$ benzalkonium chloride (BAC)bimatoprost-, 0.010\% BAC-, 0.015\% BAC-travoprost-, 0.020\% BAClatanoprost- and $0.020 \%$ BAC-treated 3D-human corneal epithelium after $24 \mathrm{~h}$ incubation without or with a $24 \mathrm{~h}$ recovery period. Antiglaucoma treatments induced a BAC-dose-dependent decrease in cell viability as assessed by the MTT test. PF-tafluprost showed a higher level of viability than all BAC-containing eye-drops. ${ }^{*} \mathrm{p}<0.01$ compared with PBS at the same time point; $\# p<0.03$ compared with $0.010 \%$ BAC at the same time point; $\$ p<0.002$ or $p<0.03$ (\$\$) compared with $0.020 \%$ BAC at the same time point; $\diamond \mathrm{p}<0.05$ compared with $0.020 \%$ BAClatanoprost at the same time point; $\mathrm{p}<0.02$ compared with $0.015 \%$ BAC-travoprost at the same time point. 
$40.1 \%$ for $0.020 \%$ BAC-latanoprost $\quad(p<0.05$ compared with PF-tafluprost, $0.005 \%$ BAC-bimatoprost and $0.015 \%$ BAC-travoprost groups, $\mathrm{p}<0.01$ compared with $\mathrm{PBS}$ and $\mathrm{p}<0.05$ compared with $0.010 \%$ BAC group), at $24 \mathrm{~h}+24 \mathrm{~h}$ recovery, $83.0 \%$ for $0.005 \%$ BAC-bimatoprost, $65.5 \%$ for $0.015 \%$ BACtravoprost $(p<0.01$ compared with $\mathrm{PBS}$ group, $\mathrm{p}<0.02$ compared with PF-tafluprost group) and $53.2 \%$ for $0.020 \%$ BAClatanoprost $(p<0.05$ compared with PF-tafluprost and $0.005 \%$ BAC-bimatoprost).

\section{Immunofluorescence analyses and quantification of apoptosis (TUNEL)}

Few apoptotic cells were observed after PBS (figure 2A) or PFtafluprost (figure $2 \mathrm{~B}$ ) incubations (figure $2 \mathrm{H}$ ): 17.0 cells/field for
PBS and 13.3 cells/field for PF-tafluprost at $24 \mathrm{~h}$; 14.5 cells/field for PBS; and 15.4 cells/field for PF-tafluprost at $24 \mathrm{~h}+24 \mathrm{~h}$ recovery. In accordance with our previous study, BAC at $0.010 \%$ and $0.020 \%$ significantly increased the number of TUNEL-positive cells at $24 \mathrm{~h}$, and at $24 \mathrm{~h}+24 \mathrm{~h}$ recovery compared with PBS group ( $p<0.02$ for $0.010 \%$ BAC, $p<0.01$ for $0.020 \%$ BAC).

The number of apoptotic cells increased after the BACcontaining antiglaucoma eye-drops in a BAC-concentrationdependent manner at $24 \mathrm{~h}$. In addition, the corneal epithelial cells could not recover after the recovery period, and more cells tended to undergo apoptosis with an increase in TUNEL-positive cells at $24 \mathrm{~h}+24 \mathrm{~h}$ recovery. Bimatoprost with $0.005 \%$ BAC (figure 3C) induced moderate expression of apoptosis (figure $2 \mathrm{H}, 23.4$ cells/
Figure 2 Apoptosis analysis: localisation of terminal deoxynucleotidyl transferase mediated dUTP nick end labelling (TUNEL)-positive cells (green) on 3D-human corneal epithelium samples after phosphate-buffered saline (PBS) (A), preservative-free (PF)tafluprost $(B), 0.005 \%$ benzalkonium chloride (BAC)-bimatoprost (C), $0.010 \%$ BAC (D), 0.015\% BAC-travoprost (E), $0.020 \%$ BAC-latanoprost (F) and $0.020 \%$ BAC $(G)$ incubation after $24 \mathrm{~h}$ without (left column) or with the $24 \mathrm{~h}$ recovery period (right column). Quantification of TUNEL-positive cells $(\mathrm{H})$ was performed after $24 \mathrm{~h}$ of treatment with all solutions followed or not by a $24 \mathrm{~h}$ recovery period. At $24 \mathrm{~h}$ or $24 \mathrm{~h}+24 \mathrm{~h}$ recovery, no or very few apoptotic cells were observed after PBS (A) or PF-tafluprost (B) treatments. Bimatoprost with $0.005 \%$ BAC (C) induced moderate expression of apoptosis, and $0.010 \%$ BAC (D), 0.015\% BAC-travoprost (E), $0.020 \%$ BAC-latanoprost (F) $0.020 \%$ BAC $(G)$ all induced a great number of TUNEL-positive cells principally in the apical cell layers, and also in the middle epithelial layers. The nuclei were stained with 4',6-diamidino-2 phenylindole (blue). The quantification of TUNEL-positive cells shows the increase in apoptotic cell number in a BAC dose-dependent manner. BAC at $0.010 \%$ and $0.020 \%$ significantly increased the number of TUNEL-positive cells at $24 h$, and at $24 h+24 h$ recovery compared with control. The antiglaucoma eye-drops travoprost and latanoprost, which contain higher concentrations of BAC, showed a much higher expression of apoptotic cells than did PF-tafluprost or control. ${ }^{*} p<0.02$ for $0.010 \%$ BAC and $p<0.01$ for other solutions compared with PBS at the same time point; $\# p<0.005$ compared with $0.010 \%$ BAC at the same time point; $\$ p<0.001$ compared with $0.020 \%$ BAC at the same time point; $\vee \mathrm{p}<0.003$ compared with $0.020 \%$ BAC-latanoprost at the same time point; $\mathrm{p}<0.03$ compared with $0.015 \%$ BAC-travoprost at the same time point.
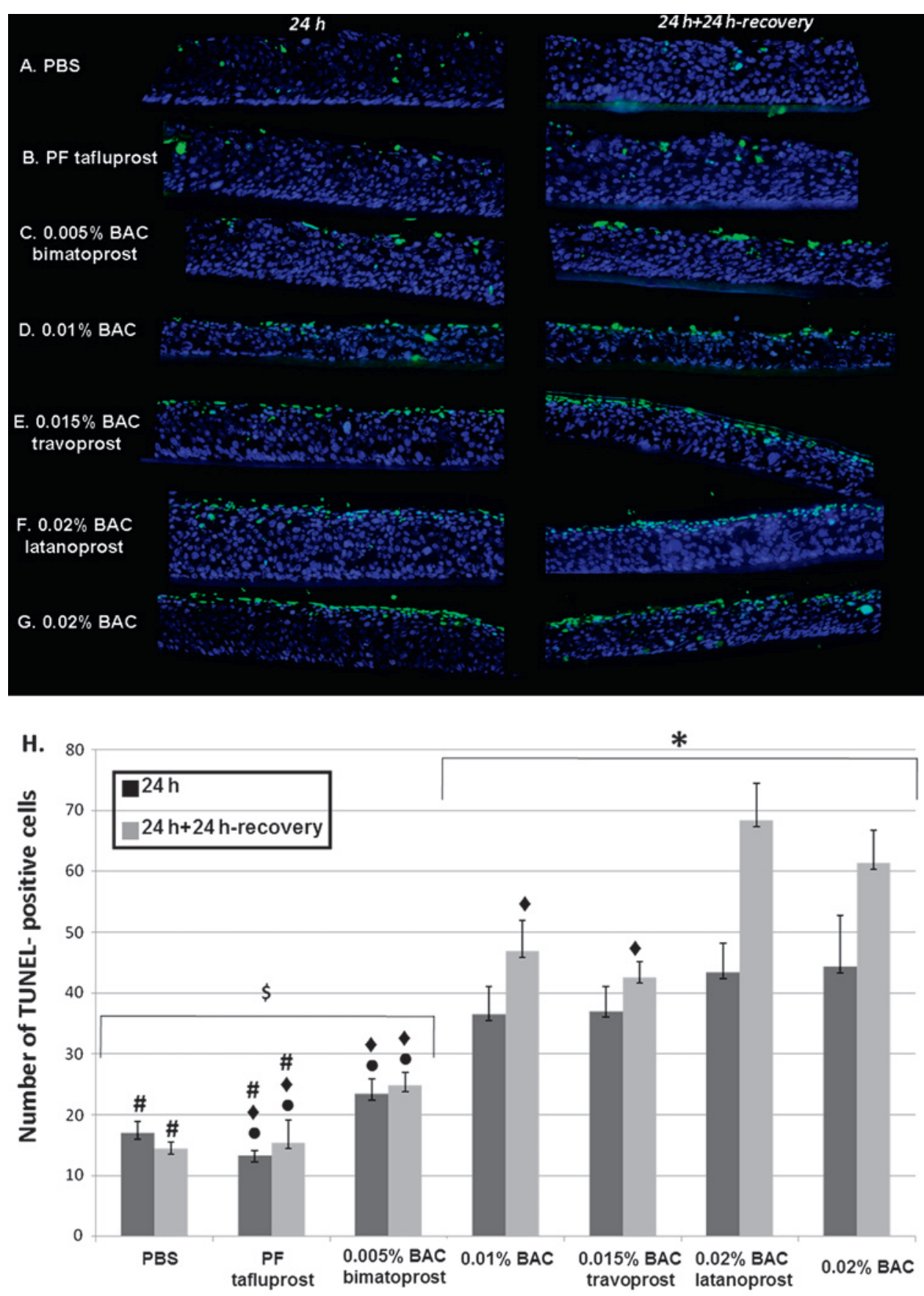
field at $24 \mathrm{~h}$ and 24.8 cells/field at $24 \mathrm{~h}+24 \mathrm{~h}$ recovery), and $0.015 \%$ BAC-travoprost (figure $2 \mathrm{E}$ ) with 37.0 cells/field at $24 \mathrm{~h}$ and 42.6 cells/field at $24 \mathrm{~h}+24 \mathrm{~h}$ recovery $(\mathrm{p}<0.03$ compared with PF-tafluprost and $0.005 \%$ BAC-bimatoprost groups at $24 \mathrm{~h}$ and $24 \mathrm{~h}+24 \mathrm{~h}$ recovery). The highest levels of apoptotic cells were found homogenously disseminated after the application of $0.020 \%$ BAC-latanoprost (figure 2F) and of $0.020 \%$ BAC (figure 2G): 43.4 cells/field and 44.3 cells/field respectively at $24 \mathrm{~h} ; 68.3$ cells/field and 61.3 cells/field respectively at $24 \mathrm{~h}+24 \mathrm{~h}$ recovery. These TUNEL-positive cells were observed especially in the apical cell layers, but also in the middle epithelial layers. Latanoprost with $0.020 \%$ BAC induced a significantly higher amount of apoptotic cells than did PF-tafluprost, $0.005 \%$ BACbimatoprost at $24 \mathrm{~h}(\mathrm{p}<0.003$ for both) and $24 \mathrm{~h}+24 \mathrm{~h}$ recovery
Figure 3 Inflammation analysis: immunolocalisation of ICAM-1 (CD54) positive cells (green) on 3D-human corneal epithelium samples after phosphate-buffered saline (PBS) (A), preservative-free (PF)-tafluprost (B), $0.005 \%$ benzalkonium chloride (BAC)bimatoprost (C), $0.010 \%$ BAC (D), $0.015 \%$ BAC-travoprost (E), 0.02\% BAClatanoprost $(\mathrm{F})$ or $0.020 \% \mathrm{BAC}(\mathrm{G})$ treatments after $24 \mathrm{~h}$ of treatment without or with the $24 \mathrm{~h}$ postincubation period. Quantification of ICAM-1 (H) was performed after $24 \mathrm{~h}$ of treatment with all solutions followed or not by a $24 \mathrm{~h}$ postincubation period. ICAM-1expressing cells were already found in the PBS (A) and PF-tafluprost (B) groups with the same level of expression after $24 \mathrm{~h}$ or $24 \mathrm{~h}+24 \mathrm{~h}$. The increase in ICAM-1 expressions was observed after the treatments with $0.005 \%$ BAC-bimatoprost (C) and $0.010 \%$ BAC (D) with and without the $24 \mathrm{~h}$ postincubation period. However, few remaining ICAM-1 positive cells were observed after treatments with $0.015 \%$ BAC-travoprost (E), $0.020 \%$ BAC-latanoprost (F) and $0.020 \%$ BAC (G) on the 3D-human corneal epithelium samples owing to the erosion. The nuclei were stained with propidium iodide (red). The quantification of terminal deoxynucleotidyl transferase mediated dUTP nick end labellingpositive cells confirmed the observations. ${ }^{*} p<0.001$ compared with PBS at the same time point; $\# p<0.005$ compared with $0.010 \%$ BAC at the same time point; $\$ p<0.0001$ compared with $0.020 \%$ BAC at the same time point; $\diamond \mathrm{p}<0.002$ compared with $0.020 \%$ BAC-latanoprost at the same time point; $\mathrm{p}<0.008$ compared with $0.015 \%$ BAC-travoprost at the same time point.
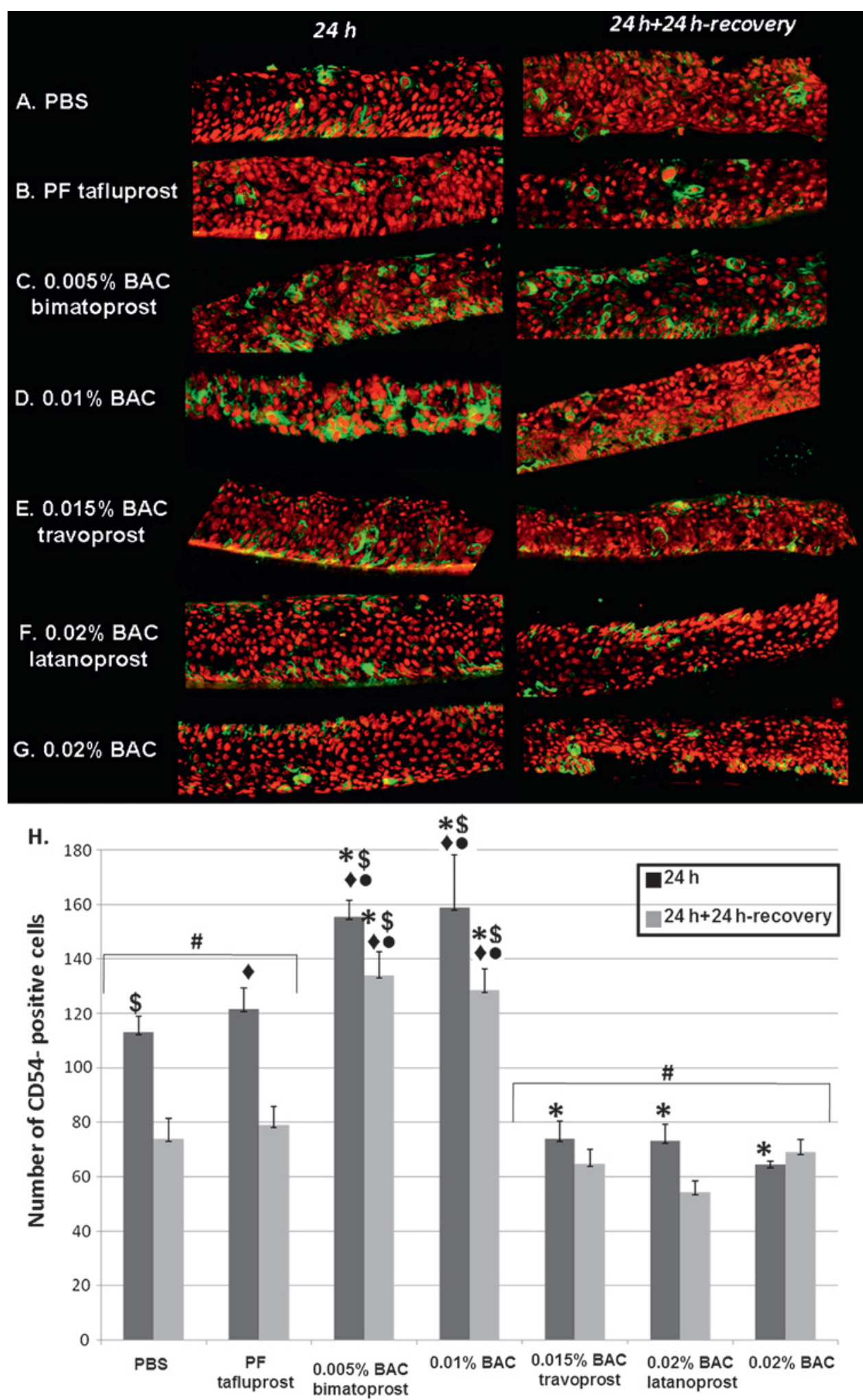
( $p<0.003$ for both), as well as $0.010 \%$ BAC and $0.015 \%$ BAC-travoprost at $24 \mathrm{~h}+24 \mathrm{~h}$ recovery $(\mathrm{p}<0.003)$.

\section{Immunofluorescence analyses and quantification of the inflammation marker: ICAM-1 (CD54)}

PBS-treated 3D-HCE cultures (figure $3 \mathrm{~A}, \mathrm{H}$ ) were found to express CD54 at levels of approximately 113.2 cells/field at $24 \mathrm{~h}$, and 74.0 cells/field at $24 \mathrm{~h}+24 \mathrm{~h}$ recovery. PF-tafluprost induced 121.5 cells/field at $24 \mathrm{~h}$ and 79.0 cells/field at $24 \mathrm{~h}+24 \mathrm{~h}$ recovery without any statistically significant differences with PBS-treated samples. BAC 0.005\%-bimatoprost induced an increase in CD54positive cells: 155.5 cells/field at $24 \mathrm{~h}$ and 134.0 cells/field at $24 \mathrm{~h}$ $+24 \mathrm{~h}$ recovery $(\mathrm{p}<0.001$ compared with $\mathrm{PBS}, \mathrm{p}<0.002$ compared with $0.02 \%$ BAC-latanoprost, $\mathrm{p}<0.008$ compared with $0.015 \%$ BAC-travoprost at $24 \mathrm{~h}$ and $24 \mathrm{~h}+24 \mathrm{~h}$ recovery). This level of increased CD54 activation was also found with $0.01 \%$ BAC: 158.8 cells/field at $24 \mathrm{~h}$, and 128.5 cells/field at $24 \mathrm{~h}$ $+24 \mathrm{~h}$ recovery $(\mathrm{p}<0.001$ compared with $\mathrm{PBS}, \mathrm{p}<0.002$ compared with $0.02 \%$ BAC-latanoprost, $\mathrm{p}<0.008$ compared with $0.015 \%$ BAC-travoprost at $24 \mathrm{~h}$ and $24+24 \mathrm{~h}$ recovery). For $0.005 \%$ BAC-bimatoprost and $0.010 \%$ BAC, the CD54 positive cells were located throughout all the epithelial layers (figure $3 \mathrm{C}, \mathrm{D}$ ). However, with higher concentrations of BAC, this number decreased, probably owing to the erosion of corneal epithelium with toxic solutions: 74.0 cells/field after $0.015 \%$ BAC-travoprost treatment, 73.3 cells/field after $0.020 \%$ BAClatanoprost treatment and only 64.3 cells/field after $0.020 \%$ BAC treatment at $24 \mathrm{~h}$ (for the three groups: $\mathrm{p}<0.001$ compared with PBS group, $\mathrm{p}<0.005$ compared with $0.010 \% \mathrm{BAC}$ ).

\section{Immunofluorescence analyses of cell proliferation: Ki67}

After PBS treatment (figure 4A), some proliferating cells were observed, not restricted to the basal layer at $24 \mathrm{~h}$ or $24 \mathrm{~h}+24 \mathrm{~h}$ recovery. PF-tafluprost induced a similar aspect as did PBStreated samples. However, more numerous proliferating cells, with a greater number located in the basal layer, were found after $\quad 0.005 \%$ BAC-bimatoprost (figure 4C), $0.01 \%$ BAC (figure $4 \mathrm{D}$ ), $0.015 \% \mathrm{BAC}$-travoprost (figure $4 \mathrm{E}$ ), $0.02 \% \mathrm{BAC}$ - latanoprost (figure $4 \mathrm{~F}$ ) and $0.02 \% \mathrm{BAC}$ (figure 4G). At $24 \mathrm{~h}+24 \mathrm{~h}$ recovery, we could still find some proliferative cells after the treatments with $\mathrm{PBS}$ or PF-tafluprost. In this time, following treatment with the solutions containing BAC $(0.010 \%$ BAC, $0.020 \% \mathrm{BAC}$, and the three BAC containing antiglaucoma solutions), no or very few proliferative cells were observed, again most likely owing to the deep impairment of corneal cells after toxic challenge.

\section{En face confocal microscopic analysis of tight junction: occludin and $\mathrm{ZO}-1$}

The 3D-HCEs revealed a thin occludin immunostaining in the most superficial cells, forming a persistent green ring around, leaving a diffuse cytoplasmic staining, after treatments with PBS (figure 5A) or PF-tafluprost (figure 5B). We still found a slight occludin expression in the apical cells with $0.005 \%$ BACbimatoprost (figure 5C). This kind of occludin expression clearly disappeared after treatments with $0.010 \%$ BAC (figure 5D), $0.015 \%$ BAC-travoprost (figure $5 \mathrm{E}$ ), $0.020 \%$ BAC-latanoprost (figure $5 \mathrm{~F}$ ) and $0.020 \% \mathrm{BAC}$ (figure $5 \mathrm{G}$ ) at $24 \mathrm{~h}$, leaving only dense green patches. After the $24 \mathrm{~h}$ recovery period, no significant change in occludin protein distribution was found compared with treatment without the recovery period. The same tendency was found using ZO-1: a thin green ring was found just after the treatment with PBS (figure 5H) or PF-tafluprost (figure 5I).

\section{DISCUSSION}

The toxicological model of 3D-reconstructed cornea epithelial model confirmed the cytotoxicity of BAC-containing solutions with a better approach of what exists in vivo or in vitro. Using a selection of pertinent biomarkers on this 3D-HCE, we detected and analysed the presence of cell apoptosis, activation/inflammation, proliferation/turnover and cellular tight junctions after application of different test solutions. This model, while respecting the ethical guidelines of animal experimentation, especially the ' $3 R$ ' rule (refining, reducing and replacing the use of animals), ${ }^{6}$ contributes to a better visualisation of the human epithelial structure than the traditional monolayer cell
Figure 4 Proliferation analysis: immunolocalisation of Ki-67 positive cells (green) on 3D-human corneal epithelium samples after phosphatebuffered saline (PBS) (A), preservativefree (PF)-tafluprost (B), $0.005 \%$ benzalkonium chloride (BAC)bimatoprost (C), 0.01\% BAC (D), $0.015 \%$ BAC-travoprost (E), $0.020 \%$ BAC-latanoprost (F) or $0.020 \%$ BAC (G) treatments after $24 \mathrm{~h}$ of treatment without (left column) or with the $24 \mathrm{~h}$ recovery period (right column). Ki67 immunostaining showed an epithelium with proliferating cells not restricted to the basal layer after PBS treatment $(A)$ at $24 \mathrm{~h}$. The same aspect was found after the treatment of PF-tafluprost (B). Numerous proliferating cells, with a great number located in all the layers, were found after the treatments of $0.005 \%$ BAC-bimatoprost (C), $0.010 \%$ BAC (D), 0.015\% BAC-travoprost (E), $0.020 \%$ BAC-latanoprost $(\mathrm{F})$ and $0.020 \%$ BAC (G) at $24 \mathrm{~h}$. At $24 \mathrm{~h}+24 \mathrm{~h}$ recovery, we observed the persistence of some proliferative cells after the treatments of PBS or PF-tafluprost. However, at this time, there were no more proliferative cells after the treatments with all BAC-containing solutions. 


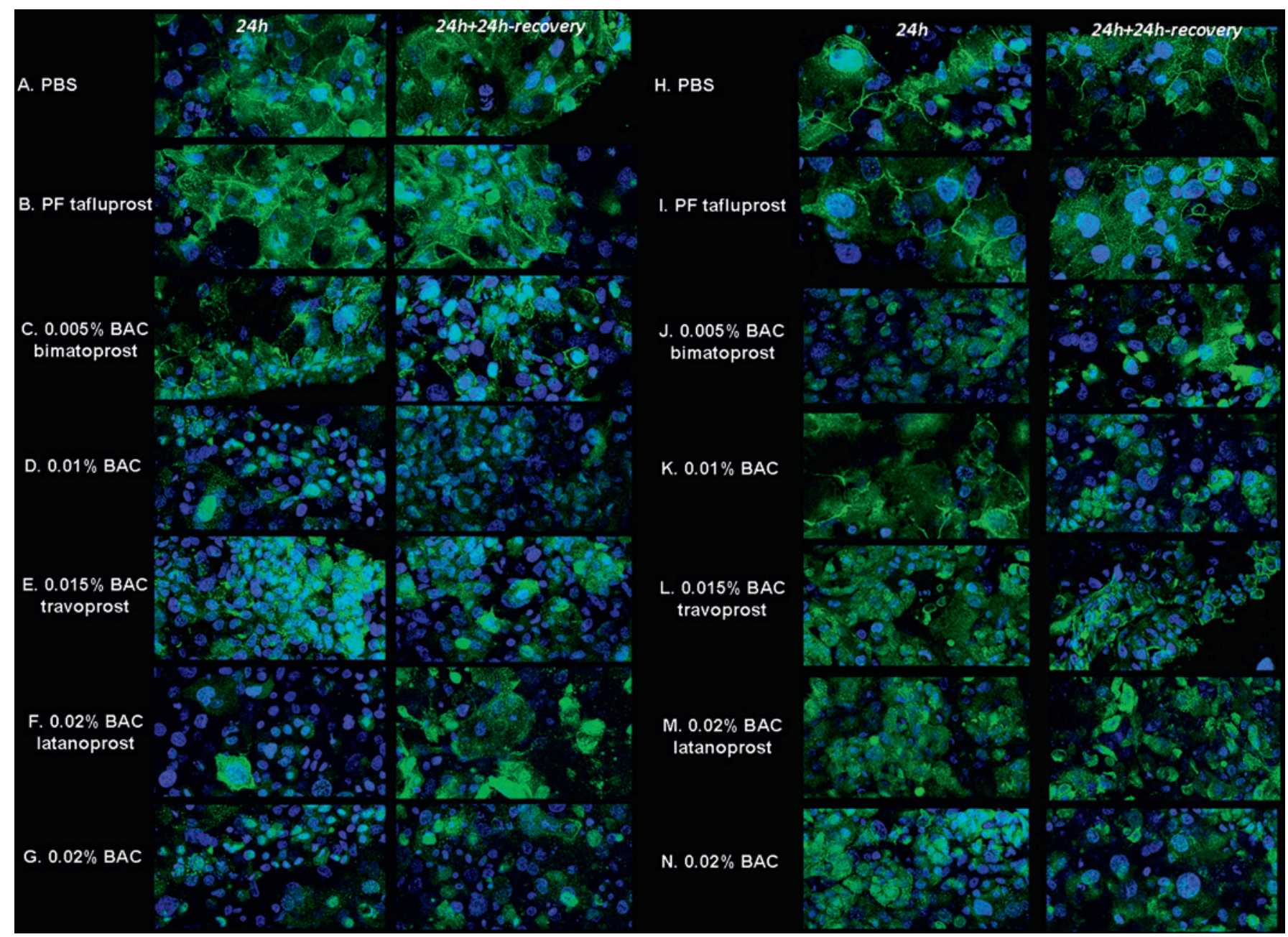

Figure 5 Tight junction: occludin and tight junction protein 1 (zona occludens 1, Z0-1). Immunofluorescence analysis of occludin (green: A to G) and ZO-1 (green: $\mathrm{H}$ to N) expressions using en face confocal microscopy after treatment with phosphate-buffered saline (PBS) (A), preservative-free (PF)tafluprost (B), $0.005 \%$ benzalkonium chloride (BAC)-bimatoprost (C), 0.010\% BAC (D), 0.015\% BAC-travoprost (E), 0.020\% BAC-latanoprost (F) and $0.020 \%$ BAC (G) treatments after $24 \mathrm{~h}$ (left column) or $24 \mathrm{~h}+24 \mathrm{~h}$ recovery (right column). The nuclei were stained with $4^{\prime}, 6$-diamidino-2-phenylindole (blue). After the treatment with PBS or PF-tafluprost, the 3D-human corneal epithelium revealed a thin occludin/ZO-1 immunostaining in the most superficial cells of samples by forming a green ring around, leaving a diffuse cytoplasmic staining. We still found a slight tight junction expression in the apical cells with $0.005 \%$ BAC-bimatoprost (C). The expressions disappeared completely after the treatments with $0.010 \%$ BAC (D), $0.015 \%$ BACtravoprost $(\mathrm{E}), 0.020 \%$ BAC-latanoprost $(\mathrm{F})$ and $0.020 \% \mathrm{BAC}(\mathrm{G})$ at $24 \mathrm{~h}$ or $24 \mathrm{~h}+24 \mathrm{~h}$ recovery, leaving dense green patches. Note that the nuclei became smaller after treatments with high-dose BAC-containing solutions.

cultures and represents a highly valuable tool between animal and cellular models for toxicity detection. The fluorescence techniques conjugated with confocal microscopy on 3Dreconstructed corneal epithelia were proven to be suitable for the investigation of toxicological markers and yielded relevant results compared with the known human data. ${ }^{5}$ As on monolayer cell cultures, the $24 \mathrm{~h}$ recovery experiments on $3 \mathrm{D}-\mathrm{HCE}$ model allow the apoptotic process to develop further and to induce the inhibition of proliferation. The expression of the proliferation marker, KI-67 nuclear antigen decreased after this $24 \mathrm{~h}$ recovery, while the apoptosis- and inflammation-related markers increased. These results confirmed that BAC, depending on the time and concentration used, acts as a pro-inflammatory and pro-apoptotic agent able to impair the normal epithelium turnover irreversibly, even after BAC withdrawal. Several in vitro studies have already revealed these deleterious effects of $\mathrm{BAC}$ and BAC-containing antiglaucoma drugs. The MTT assay is a simple quantitative method usually used to assess the cell viability in these 3D-HCE models. ${ }^{7}$ It seems more reliable and robust than immunofluorescence and confocal microscopy, which are known to provide visual and convincing results for the analysis of cell damage; however, these techniques are deemed to give adjunct results for the purpose of comparison of tested solutions. But, even if based on a smaller number of cells and a quantitative reading that depends on the experimenter, we proved in this study that these techniques also allow quantification and provide a good understanding of all toxic phenomena and their impact on various biological processes. Consistent with similar analyses in monolayer cell cultures and in the rabbit model, in the present study using this new 3D model, we demonstrated that PF-tafluprost presented almost the same aspects as did the negative control with persistent epithelial cell tight junctions and the appropriate proliferative level, with no induction of cellular apoptosis or inflammation when compared with the formulations containing toxic preservative BAC. BACinduced ocular toxicity has been well documented in cell culture, animal models and patients. ${ }^{8}$ The reconstituted $3 \mathrm{D}-\mathrm{HCE}$ model, resembling the corneal epithelium of the human eye in 
morphology and thickness, ${ }^{9}$ was already used as a new alternative to the classic Draize eye test for the assessment of the eye irritation potential of chemicals and cosmetic products. ${ }^{4}{ }^{10}$ It confirmed the cytotoxicity of BAC, and this model was sensitive enough to distinguish between different concentrations of BAC, from $0.001 \%$ to $0.5 \% .^{5}$ The versatility and sensitivity of the $3 \mathrm{D}$ HCE models were also investigated, and this model was proposed to replace some uses of animal testing in preclinical studies. In addition, the occludin gene expression was proposed as an early in vitro sign for assessment of mild eye irritation. ${ }^{11}$

Even though multiple studies consistently showed BAC toxicity and potential advantages of BAC-free compounds, ${ }^{8}$ there still exists some debate as to its cytotoxicity in ocular tissues and potential harmfulness for glaucoma patients. In contrast with our results and all literature data on BAC, ${ }^{8} 12-19$ one recent study did not find any loss of viability when testing $\mathrm{BAC}$ alone or BAC-containing latanoprost after a short contact duration from 10 to 60 min using the same model of 3Dcorneal epithelium as that used in this study. ${ }^{20}$ These conflicting results were principally due to the differences in experimental conditions, such as the choice of model or appropriateness of duration of contact. In patients, the age, the quality of tear film, the individual sensitivity of the ocular surface, a pre-existing sensitivity or allergy, and the overall number of BAC-containing eye-drops and duration of administration could all be considered to influence the impact of toxic preservative on ocular tissues and may explain wide individual variations. In experimental conditions, the contact duration of $\mathrm{BAC}$ is essential to consider and may explain some apparently conflicting results: Khoh-Reiter and Jessen stated in their study that $\mathrm{BAC}$ is in contact with the eye structures only for a few seconds after instillation. Another study proved that a rapid dilution in the tear film reduced the concentration of BAC to almost zero in minutes. ${ }^{21}$ However, Champeau et al detected the presence of BAC in the conjunctival epithelium 9 days after a single administration, which suggests prolonged impregnation of BAC in ocular tissue instead of simple dilution in tear film. ${ }^{22}$ In rabbits, radiolabelled BAC was found in the palpebral and bulbar conjunctiva and all corneal layers, and single-drop administration resulted in high tissue levels in the anterior ocular tissues remaining for up to $120 \mathrm{~h}^{23}$

In our model of a 3D culture of corneal epithelium, a $24 \mathrm{~h}$ incubation was therefore considered to better mimic the accumulation of BAC over the long term and allowed a better investigation of the cell alterations in the deeper layers of the corneal epithelium. As BAC is usually considered a potent and useful enhancer of drug penetration into deep ocular structures, all experimental models should be considered in light of a significant contact time, depending not on tear concentrations of BAC but on much more prolonged contact times, as most likely occurs with a compound that impairs the tear film, disrupts cell membranes, increases corneal epithelium permeability and is repeatedly used over extremely long periods of time. ${ }^{8}$ Complementarily, the $24 \mathrm{~h}$ recovery appeared justified as for the monolayer cultures for evaluating late effects, either in terms of possible compensation and recovery or as an amplification of toxic reactions.

In conclusion, our results using the new 3D-HCE model for evaluating BAC-containing prostaglandin analogues and PFtafluprost were in accordance with previously published works investigating BAC toxicity. The present study provides a valuable method to evaluate the impacts of eye-drops in vitro, being more accurate than single monolayers and easier to perform than animal models. The development of 3D-HCEs thus enriches the existing models to study the bioactivity of eyedrops in the cornea by investigating and quantifying a set of cellular functions such as cellular viability, inflammation, proliferation, apoptosis or cell junctions.

Funding The study was supported by an unrestricted grant from Santen Oy (Tempere, Finland).

\section{Competing interests None.}

Provenance and peer review Not commissioned; externally peer reviewed.

\section{REFERENCES}

1. Nakajima T, Matsugi T, Goto W, et al. New fluoroprostaglandin F(2alpha) derivatives with prostanoid FP-receptor agonistic activity as potent ocularhypotensive agents. Biol Pharm Bull 2003:26:1691-5.

2. Brasnu E, Brignole-Baudouin $F$, Riancho $L$, et al. In vitro effects of preservative-free tafluprost and preserved latanoprost, travoprost, bimatoprost in a conjunctival epithelial cell line. Curr Eye Res 2008;14:204-16.

3. Liang $\mathbf{H}$, Baudouin C, Pauly A, et al. Conjunctival and corneal reactions in rabbits following short- and repeated exposure to preservative-free tafluprost, commercially available latanoprost and $0.02 \%$ benzalkonium chloride. $\mathrm{Br} \mathrm{J}$ Ophthalmol 2008;92:1275-82.

4. Doucet 0, Lanvin M, Thillou C, et al. Reconstituted human corneal epithelium: a new alternative to the Draize eye test for the assessment of the eye irritation potential of chemicals and cosmetic products. Toxicol In Vitro 2006;20:499-512.

5. Pauly A, Meloni M, Brignole-Baudouin F, et al. Multiple endpoint analysis of the 3D-reconstituted corneal epithelium (SkinEthic ${ }^{\mathrm{TM}}$ ) after treatment with benzalkonium chloride: modified MTT procedure and new markers for the early detection of toxic damage. Invest Ophthalmol Vis Sci 2009:50:1644-52.

6. Manciocco A, Chiarotti F, Vitale A, et al. The application of Russell and Burch 3R principle in rodent models of neurodegenerative disease: the case of Parkinson's disease. Neurosci Biobehav Rev 2009;33:18-32.

7. Cotovio J, Grandidier MH, Lelièvre D, et al. In vitro assessment of eye irritancy using the Reconstructed Human Corneal Epithelial SkinEthic HCE model: application to 435 substances from consumer products industry. Toxicol In Vitro 2010;24:523-37

8. Baudouin C, Labbé A, Liang $\mathrm{H}$, et al. Preservatives in eyedrops: the good, the bad and the ugly. Prog Retin Eye Res 2010;29:312-34.

9. Nguyen DH, Beuerman RW, De Wever B, et al. Three-dimensional construct of the human corneal epithelium for in vitro toxicology. In: Salem H, Katz SA, eds. Alternative Toxicological Methods. Boca Raton, FL: CRC Press, 2003:147-59.

10. Doucet O, Lanvin M, Zastrow L. A new in vitro human epithelial model for assessing the eye irritating potential of formulated cosmetic products. Vitro Mol Toxicol 1998;11:315-51

11. Meloni M, Pauly A, Servi BD, et al. Occludin gene expression as an early in vitro sign for mild eye irritation assessment. Toxicol In Vitro 2010;24:276-85.

12. Baudouin C, Garcher C, Haouat N, et al. Expression of inflammatory membrane markers by conjunctival cells in chronically treated patients with glaucoma. Ophthalmology 1994;101:454-60.

13. Baudouin C, Hamard $\mathrm{P}$, Liang $\mathrm{H}$, et al. Conjunctival epithelial cell expression of interleukins and inflammatory markers in glaucoma patients treated over the long term. Ophthalmology 2004;111:2186-92.

14. De Saint Jean M, Brignole F, Bringuier AF, et al. Effects of benzalkonium chloride on growth and survival of Chang conjunctival cells. Invest Ophthalmol Vis Sci 1999; 40:619-30

15. Pisella PJ, Debbasch C, Hamard P, et al. Conjunctival proinflammatory and proapoptotic effects of latanoprost and preserved and unpreserved timolol: an ex vivo and in vitro study. Invest Ophthalmol Vis Sci 2004;45:1360-8.

16. Asbell PA, Potapova N. Effects of topical antiglaucoma medications on the ocular surface. Ocul Surf 2005; 3:27-40.

17. Leung EW, Medeiros FA, Weinreb RN. Prevalence of ocular surface disease in glaucoma patients. J Glaucoma 2008;17:350-5.

18. Hong J, Bielory L. Allergy to ophthalmic preservatives. Curr Opin Allergy Clin Immunol 2009;9:447-53.

19. Guenoun JM, Baudouin $\mathbf{C}$, Rat $\mathrm{P}$, et al. In vitro study of inflammatory potential and toxicity profile of latanoprost, travoprost, and bimatoprost in conjunctiva-derived epithelial cells. Invest Ophthalmol Vis Sci 2005;46:2444-50.

20. Khoh-Reiter S, Jessen BA. Evaluation of the cytotoxic effects of ophthalmic solutions containing benzalkonium chloride on corneal epithelium using an organotypic 3-D model. BMC Ophthalmol 2009;9:5.

21. Friedlaender $\mathbf{M H}$, Breshears $\mathrm{D}$, Amoozgar $\mathrm{B}$, et al. The dilution of benzalkonium chloride (BAC) in the tear film. Adv Ther 2006;23:835-41.

22. Champeau EJ, Edelhauser HF. Effect of ophthalmic preservatives on the ocular surface: conjunctival and corneal uptake and distribution of benzalkonium chloride and chlorhexidine digluconate. In: Holly FJ, ed. The Preocular Tear Film. Lubbock, TX: Dry Eye Institute, 1986.

23. Green K, Chapman J. Benzalkonium chloride kinetics in young and adult albino and pigmented rabbit eyes. Cutan Ocul Toxicol 1986;5:133-42. 